\title{
The European Journal of Ageing continues to expand in scope and impact
}

\author{
H. Litwin • D. J. H. Deeg • H.-W. Wahl
}

Published online: 29 January 2015

(C) Springer-Verlag Berlin Heidelberg 2015

The European Journal of Ageing continues to expand in scope and impact. The year that begins with this issue already marks the 12 th year since the inception of the journal, the 11th year since publication of four issues per year (2004 saw the publication of one initial issue only), and the 5th year since the journal received its first impact factor from Thomson ISI. In terms of scope, 47 manuscripts were submitted to the journal in its first full year of operation back in 2005. In comparison, we received 161 submissions in our latest full year of publication. The submission rate for 2014 is, therefore, some three and a half times the rate obtained in our first full year of publication and almost twice as much as the rate recorded only 4 years ago, in 2010. The increase in submissions has been matched by an increasingly competitive response rate for EJA. A rough estimate based upon the manuscripts processed in 2014 reveals that less than a fifth of the papers submitted were accepted for publication. This acceptance

H. Litwin $(\bowtie)$

Paul Baerwald School of Social Work \& Social Welfare, Israel Gerontological Data Center, The Hebrew University in Jerusalem, Mount Scopus, 91905 Jerusalem, Israel

e-mail: eja@mail.huji.ac.il

D. J. H. Deeg

Department of Epidemiology and Biostatistics/LASA, VU University Medical Centre, Van der Boechorststraat 7, 1081 BT Amsterdam, The Netherlands e-mail: eja@vumc.nl

H.-W. Wahl

Department of Psychological Aging Research, Heidelberg University, Institute of Psychology, Bergheimer Strasse 20, 69115 Heidelberg, Germany

e-mail: eja@psychologie.uni-heidelberg.de rate is in the magnitude of that reported in other highlyranked journals.

We can also proudly reflect on the growing impact of the European Journal of Ageing among scholars. The latest figures available from Thomson ISI (2013) reveal that the journal attained a 2-year impact factor of 1.262, placing it in 15 th place among the 31 journals included in the category of gerontology. This is quite a respectable ranking, one that places EJA alongside the more established and veteran journals in the field. However, 2-year impact factors sometimes do a disservice to journals in fields such as ours that do not tend to have quick publication turnover. For that reason, it is appropriate to take into account the 5-year impact factor, which more accurately reflects the citation time that occurs in the disciplines that contribute to our field of inquiry. Looking at the 5-year impact factor from Thomson ISI, we see that EJA was assigned a score of 1.857. This ranking places our journal 12th among the gerontology journals, (that is, squarely within the second quartile). The current citation record thus clearly indicates that the European Journal of Ageing has already had a significant impact on the field.

Another way to gauge impact is to take into account a wider realm of publications, as may be seen by means of the Harzing Publish or Perish Index which produces the $\mathrm{H}$-index. This index includes electronic citations and, thus, reflects a greater breadth of publication types. Perusal of the latest statistics that are listed for EJA on the HPOP website reveals that after exclusion of editorials and similar commentary published in the journal, some 307 articles are listed (this includes those currently on-line in the Springer EJA website), and well over 5,000 citations of the articles published in EJA. The HPOP figures also indicate that on average, there are some 17 citations for each article published in our journal. However, this figure also includes the 
articles published from 2013 on and takes account of those that are currently on-line but not yet in hard copy. Such recent articles are not likely to be cited in such a short time frame. Looking at only the articles published in EJA between 2004 and 2012, those most likely to have been cited already, we find that $86 \%$ of the articles have been cited at least five times. Moreover, only one half of one percent of the articles were cited only once or not at all. It is clear, therefore, that the authors whose works are published in our journal are having an important effect in spreading new insights and new ideas.

A brief glance at the EJA articles that were most frequently cited in the respective indices provides some additional insights as to what are the topics of major concern to gerontological researchers today. While we do not have the space here to offer a full formal analysis of the trends, we can note that three of the six most frequently cited EJA articles that are listed in Thomson ISI's Web of Science deal with loneliness (Dykstra 2009; Scharf and Gierveld 2008; Sundstrom et al. 2009). The interpersonal milieu in late life is a domain that is already well covered among the publications that appear in the European Journal of Ageing and we look forward to continued inquiry in this crucial area. Another two of the most frequently cited EJA articles relate to aspects of health and functioning, areas of major concern in the study of the older population (Andersen-Ranberg et al. 2009; Zijlstra and Aminian 2007). We expect to receive additional cutting-edge submissions in this critical domain.

EJA will be continuing with its practice of periodically offering special sections about topics of interest. The last issue of the previous volume offered a special section on ageing in Portugal, a country about which more needs to be known. The respective articles in that special section explored the financial state of older Portuguese adults and particularly the curious recent reduction in poverty in the older population, the unique aspects of informal support in the Portuguese context as well as the surprisingly low rates of intergenerational transfers, and the use of a Portuguese version of the abbreviated UCLA Loneliness Scale.

The current issue of EJA includes a special section of works on the theme of "Retirement and Work." Guestedited by Dr. Michał Myck from the Centre for Economic Analysis in Szczecin, Poland, this special section is introduced more fully by the introductory article to the section, written by Dr. Myck, which appears next. Suffice it here to say that as the Editors of EJA, we welcome the debate on the future of retirement and work, as changes in these venerable societal institutions are necessarily forthcoming as populations continue to age.

The special sections published periodically in EJA are generally accompanied by articles that were accepted through the regular submission process, works that add to the state of knowledge in the wide range of areas of interest to the readers of the journal. We are pleased to note in this regard that the current issue includes three such studies. The article by Hansen and Slagsvold relates to the theme of the current special section. It suggests that combining work and caregiving does not necessarily harm well-being, as is frequently believed. The analysis by Solé-Auró and Alcañiz reports on an increase in the expectation of life with mobility limitations in Catalonia, pointing to a trend that will require increasing attention. Finally, the study by Gumà et al. reveals no differences between those with a partner and single people in terms of the retrospective hazards of poor health, raising some doubts as to the long term health protection that marriage is believed to provide over time.

Finally, we note that this issue appears shortly before the commencement of the IAGG-ER 8th Congress to be held in Dublin from April 23-26, 2015. This is a unique opportunity to offer the organizers of the conference the very best wishes of the EJA community for a successful conference. It is our hope that important new studies and critical insights with relevance for emerging areas of interest in gerontology that will be presented at the Dublin conference find their way into print via the European Journal of Ageing. We invite the participants of the Dublin conference to keep EJA in mind as they seek to publish their newest findings.

\section{References}

Andersen-Ranberg K, Petersen I, Frederiksen H, Mackenbach JP, Christensen K (2009) Cross-national differences in grip strength among $50+$ year-old Europeans: results from the SHARE study. Eur J Ageing 6:227-236

Dykstra PA (2009) Older adult loneliness: myths and realities. Eur J Ageing 6:91-100

Scharf T, de Gierveld JJ (2008) Loneliness in urban neighbourhoods: an Anglo-Dutch comparison. Eur J Ageing 5:103-115

Sundstrom G, Fransson E, Malmberg B, Davey A (2009) Loneliness among older Europeans. Eur J Ageing 6:267-275

Zijlstra W, Aminian K (2007) Mobility assessment in older people: new possibilities and challenges. Eur J Ageing 4:3-12 